\title{
INVESTLATION OF AN EPIDEMIC OF MENINGITIS IN BARUTEN LOCAL GOVERNMENT AREA OF KWARA STATE, NIGERIA
}

\author{
Akande, T. M., Monehin, J.O.
}

\author{
Department of Epidemaiology and Community Health \\ Univeraity of Iloxin Teaching Fospital, 14M 145, Ilorin, Nigexfa
}

Corgespondence to: Dr. J.O Monehin

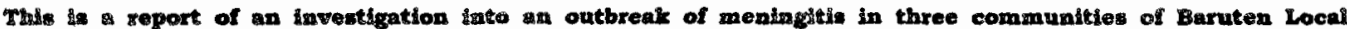
Goveramenf Area (LOA) of Kwrex state, Nigeria. A total of 41 cases of cerebronpinal meningitis (CSM) were reported. There was preponderance of males $(78 \%)$. Thirty-eight $(92.7 \%)$ did not receive csf vaccine while the remaining $3(7.3 \%)$ that receive the vaccine were vaccinated less than a week before the onset of illnews. Case Fataile Rate (CKR was 7.3\%. About half (46.3\%) of the cases were ared between 6-15 years. The outhreal could bave ben prevented if adequate supplies of CsM vaccine were provided and vaccination conducted earily enough. Covernment polley of mars immunization agrinat meningitis in November of every year should be implemented and properiy monitored to prevent future outbreals of meningitis and its resultant moxbidity and mortality.

Rey worda; Cerebroapinal meningitis, Outbreak, Kwara Btate, Nigeria.

\section{ITTRODUCTTION}

Meningococcal infections are endemic in the northern savannah region of tropical Africa and approximately every 10 years, severe epidemics occur. This area is traditionally called the meningitis belt of Africa' and extends from the Gambia, in the west, to Ethiopia, in the east. This region is characterized by an annual rainfall of $300-1100 \mathrm{~mm}$ (1). In the sub-Saharan region, meningitis occurs on an annual basis. Epidemics occur at the start of the long, dusty dry season, which is associated with very low humidity, and ends abruptly at the onset of the rains.

Epidemic meningitis in subSaharan Africa is primarily due to group A Neisseria meningitidis, which causes the cycles of meningitis in the region. During an epidemic, one person in every hundred may become ill (2). Meningitis presents clinically usually as an acute illness, with fever, intense headache, nausea and vomiting, stiff neck and often a skin rash. Delirium and coma commonly occur and case fatality rate in untreated cases is about $50-80 \%$ (3). Epidemics of meningitis have been reported in the recent past in some areas of Kwara State. These include Kaiama LGA, which shares a boundary with Baruten LGA in 1997 and in Edu LGA in 2000 (4).

Prevention of meningococcal disease has been attempted by the administration of bivalent meningococcal $A+C$ polysaccharide vaccine and there is evidence supporting the efficacy of group A vaccine from a number of African countries (5). This is a report of the investigation of the outbreak of meningitis that occurred in some communities in Baruten LGA between January and March 2001 with highlights of constraints found during the investigation and control of the epidemic.

\section{MATERIALS AND METHODS}

\section{Study area}

Baruten Local Government Area is located in the northwestern part of Kwara State of Nigeria. It is one of the largest LGAs in Kwara State both in terms of land mass and population. The projected population for the year 2001 is about 265,000 . The LGA is divided into 4 districts namely Okuta, Yashikira, and Gwanara and Ilesha-Baruba districts. The LGA headquarters is located at Kosubosu in Yashikira district. The LGA is bounded in the north by Niger State, in the south by Oyo State, in the east by Kaiama LGA 
of Kwara State and in the west by Republic of Benin.

Three communities in the LGA were visited; Ilesha-Baruba, located in the southern part, Shiya, located north of Ilesha-Baruba and Okuta, located between the two. There were two types of houses built in the LGA; modern brick houses roofed with zinc/asbestos sheets and mud houses roofed with thatched leaves. While the former is commonly seen in the more urban settings, the latter abound more in the rural communities and farm settlements. The brick houses had windows and doors and therefore are more ventilated than the mud houses that are poorly ventilated. There were only two medical doctors practicing in the whole LGA, one at the government-owned comprehensive health centre in IleshaBaruba and the other in the missionaryowned Baptist hospital in Okuta. In addition, there is a cottage hospital, 4 basic health centres and several private clinics, dispensaries and village health posts.

\section{Outbreak investigating team}

An emergency health team consisting of epidemiologists and staffs of the Disease Surveillance and Notification (DSN) unit of the Epidemiology Division of Kwara State Ministry of Health were mandated to investigate and control the outbreak of meningitis in some of the communities in Baruten LGA. The team also included a resident doctor from the Department of Epidemiology and Community Health, University of Ilorin Teaching Hospital, who provided technical support.

\section{Data collection}

Data were obtained from the records of the various health facilities in the communities affected. The Federal
Ministry of Health case definition for cerebrospinal meningitis, which describes a case as acute illness with fever, intense headache, nausea and vomiting, stiff neck and a skin rash with delirium and coma often occurring and death common in untreated cases, was employed (2). Information obtained from patients who fit the case definition included name, age, sex, address, history of previous CSM immunization and time, date of presentation to the health centre, state of consciousness at and during admission and outcome/complications. Additional information was also obtained from the Baruten Local Government Council and the Kwara State Ministry of Health.

\section{Sample collection/processing}

Cerebrospinal fluid (CSF) samples were collected from 2 cases that were admitted less than 12 hours before the investigating team arrived. The specimens were transported and processed at the medical microbiology laboratory of the University of Ilorin Teaching Hospital using standard bacteriologic techniques.

\section{Intervention measures}

Intervention measures include mass CSM vaccination and administration of long-acting oily chloramphenicol injection (Tifomycin) to cases seen during the investigation.

\section{RESULTS}

A total of 41 cases presented at the health facilities located in the 3 communities visited with case definition of CSM (Table 1). Thirty-two (78\%) of these were males while $9(22 \%)$ were females. Over $95 \%$ of cases were less than 30 years and less than $5 \%$ were above 30 years. The median age was 14.8 years. (Table 2 and 3)

In the communities, 12 of the 18 patients on admission at the time of visit 
were cases of meningitis, constituting $66.7 \%$ of total hospital admission. Of these, only 3 patients claimed to have received the CSM vaccine and all 3 took the vaccine less than $I$ week before presenting with the illness. They all recovered consequently and were discharged without complications. The remaining 38 cases gave no history of previous CSM vaccination.

Of the 41 cases, 3 died giving a case fatality rate of $7.3 \%$. Eight of the 41 cases were fully conscious before, during or after treatment. Thirty-three were however unconscious at one time or the other during the illness. Only one out of the 38 surviving cases developed complication. The case was a 22 year-old male who developed left knee arthritis.

The two CSF samples collected were turbid and both showed Gramnegative cocci on Gram-staining. The samples were obtained from 2 males aged 12 and 15 years presenting 6 and 18 hours respectively before ispecimen were taken. CSF white blood cell count was 292 cells $/ \mathrm{ml} \quad 160 \%$ polymorphs, $40 \%$ lymphocytes) for the first patient and 208 cells $/ \mathrm{ml} \quad(76 \%$ polymorphs, $24 \%$ lymphocytes) for the second patient. None of the sample grew any pathogen on culture.

Record of CSM vaccines supplied to Baruten LGA from the beginning of year 2000 showed that about 27,200 doses were supplied from Kwara State Ministry of Health. This will only immunize about $10 \%$ of the estimated population. Mass vaccination was however not commenced in the area until the first few cases were recorded from the southernmost district of Gwanara in late January 2001. Mass vaccination actually began in the LGA in early February 2001.

Table 1: Cases presenting at the health faclities that met the aritoris for cave cefinition of Meningitis in Hesha-Baruba, Okuta and shiga communities

\begin{tabular}{|c|c|c|c|c|c|}
\hline \multicolumn{3}{|c|}{ Date } & Ilesha-Baruba & osinte & Ehiym \\
\hline February & 1.7 & 2001 & 0 & 0 & 0 \\
\hline February & $8-14$ & 2001 & 3 & 1 & $\overline{0}$ \\
\hline February & $\overline{15}-\overline{21}$ & 2001 & 7 & 6 & 0 \\
\hline February & $22 \overline{28}$ & 2001 & 7 & 14 & $\overline{3}$ \\
\hline Total & & & 17 & 21 & 3 \\
\hline
\end{tabular}

Table 2: Bex distribution of people affected

\begin{tabular}{|c|c|c|}
\hline Sex & Frequency & Percentage $(\%)$ \\
\hline Male & 32 & 78 \\
\hline Female & 9 & 22 \\
\hline Total & 41 & 100 \\
\hline
\end{tabular}

Talle a: Age dintritiontion of people afrected

\begin{tabular}{|c|c|c|}
\hline $\begin{array}{l}\text { Apo poup } \\
\text { neares }\end{array}$ & Freguency & Percentage $8 \%$ \\
\hline $1-5$ & 5 & 12.2 \\
\hline $6-10$ & 5 & 12.2 \\
\hline $11-15$ & 14 & 34.1 \\
\hline $86-20$ & 6 & 14.6 \\
\hline $21-25$ & 5 & 12.2 \\
\hline $20 \times 30$ & 4 & 9.8 \\
\hline Absuc 30 yen: & 2 & 4.9 \\
\hline 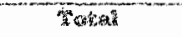 & 43 & 200 \\
\hline
\end{tabular}


DIscussion

The pattern of meningococcal infections in African epidemics is similar to that in developed countries whiere meningitis is by far the commonest presentation in over $80 \%$ of cases (6). There has been no reported outbreak of meningitis in the entire Local Government investigated in several years. The first community to be affected among the three was Ilesha-Baruba in the second week of February 2001. Okuta community was later affected the same week. Shiya community did not record any case until the fourth week of February. While the epidemic peaked in llesha-Baruba community in the third week of February and appeared to be subsiding by the fourth week, it was still raging in Okuta community by the third and fourth week of February. Shiya community, located north of koth Okuta and Ilesha-Baruba communities recorded its first few cases in the 4th week of February. This spread to contiguous regions was observed in a similar epidemic in Katsina State in 1996 where the occurrence of cases in a community was one of the major criteria used in assessing mriority on the need to vaccinate neighboring communities (3). The spread through droplet infection could have been aided by the weekly major market days in Ilesha-Baruba and Okuta where people from far and near come to carry out commercial activities.

The higher number of males (78\%) affected in this epidemic may be due to an increased opportunity to acquire the infection by males compared to females rather a genetic sex predisposition to the infection (7). However, while some studies showed almost equal sex distribution of the cases, others give results showing higher affectation of male. For example, the 1996 epidemic in Katsina state (3) showed that half of the 20,927 cases registered, were males. In the same epidemic around the same period in neigbouring Kano State (1), the male: female ratio of cases was 1.94: 1 compared to $3.56: 1$ recorded in our study.

The age group most affected is the 11-15 years age group constituting over one-third of all the cases. The median age affected was 14.8 years. This is similar to the report of the 1996 Kano epidemic study where $50 \%$ of all cases seen at the Infectious Diseases Hospital, Kano were between 6-15 years. About $46.3 \%$ of cases seen in the various health facilities in the 3 communities assessed in the study were also within the 6-15 years age group. Whereas $8 \%$ of cases were older than 30 years in the Kastina study, $4.9 \%$ of cases seen were above 30 years in the present study. It has been documented that relatively more cases odcurs in the 5-19 years age group during epidemic than non-epidemic period (8). The fact that only one patient was aged less than 2 years corroborated the observation that children less than 2 years old may be spared during epidemics (5). Also, the fact that about two-third of the patients seen in the various hospitals were cases of meningitis is an indication of the amount of pressure the outbreak had placed on the available health facilities.

Of the 41 cases, $38 \cdot(92.7 \%)$ did not receive the CSM vaccine in the past 5 years. All the remaining 3 cases only took the vaccine less than a week to the date of presentation. It is in line with the observation that the vaccine may not offer protection until after 7 days of its administration (9). The observed Case Fatality Rate of $7.3 \%$ among the cases presenting at the various health centres is 
similar to the $7: 8 \%$ found in the Kano study. Most of the fatal cases died within few hours of admission. All the cases were among those who were unconscious before or at admission. Although no record of coma scale rating was available, level of consciousness could still serve as a prognostic index (1). Only one patient developed complication of left knee arthritis after apparent recovery from the infection. This was thought to be an immune-complex mediated reaction, which usually resolves without any sequelae (10).

The laboratory results of the CSF samples from the 2 patients, though confirmed the diagnosis of pyogenic meningitis from microscopy, did not yield any growth on culture. The result of the Gram-stain showing Gram-negative cocci suggests the likely organism in epidemic meningitis, Neisseria meningitidis. The organism is known to be very fastidious and dies rapidly on exposure to heat or cold (7) hence this may explain our failure to isolate it on culture. Lack of appropriate media for transportation of specimen and the long distance between the communities and University of Ilorin Teaching Hospital, where the specimens were cultured could be additional factors responsible for our inability to isolate the organism. This raises the need to equip zonal public health laboratories in the states.

The housing condition of the communities if improved with better ventitilation will go a long way in long-term control of meningitis in the areas. The prolonged delay in carrying out mass vaccination in Baruten LGA contributed to the occurrence of the epidemic. Also, the delay in reporting to the hospital by most patients resulted in a higher number of patients presenting with unconsciousmess before or during admission and with consequent adverse effect on the prognosis. Puture outbreaks can be better prevented by ensuring that mass vaccination is carried out by the month of November every year as recommended by the Federal Ministry of Health. Improving housing condition in the rural communities and involving the communities in early recognition, detection and immediate reporting to the hospital will assist in these areas where health facilities are very limited.

\section{REPERETCE:}

1. Ajayi-Obe EK, Lodi E, Alkali AS, et al. Prognostic scores for use in African meningococcal epidemic. Bull. World Hith. Org. 1998; 76(2): 149-152

2. Federal Ministry of Health. Cerebrospinal meningitis (CSM). Nig. Bull. Epidemiol. 1991; 1(3): 21

3. Veeken $\mathbf{H}$, Ritmeijer $\mathbf{K}$, Hausman $B$. Priority during a meningitis epidemic: vaccination or treatment? Bull. World Hith Org. 1998; 76(2): 135-141.

4. Akande TM, Olu $O$. Perception and attitude to outbreak of meningitis in rural area. Nig. J. Med. 1998; T(4): 153-156

5. Wright PE. Approaches to prevent acute bacterial meningitis in developing countries. Bull. World Hith. Org. 1989; 67(5): 479-486.

6. Federal Ministry of Health. Emergency preparedness and response to epidemics/case management. Federal Ministry of Health, Lagos. April 1996.

7. Harry N, Beaty. Meningococcal infections. In: Petersdorf $\mathbf{R}$, Adam $\mathbf{R}$ Braunwald $\mathbf{E}$, Isselbacher $\mathbf{K}$, Martin, $\mathbf{J}$, Wilson J. (eds.). Harrison's Principles of Internal Medicine. 10th edition. McGraw-Hill Inc., New York, 1983: 935-939.

8. Peltola H, Kataja JM, Makela PH. Shift in the age distribution of meningococcal disease as a predictor of an epidemic. Lancet. 1982; 2: 595 . 597

9. Robert Steffen. Infectious Diseases Prevention in the International Traveller. In: William $N$ Kelley (Ed.). Textbook of Internal Medicine. $3^{\text {ro }}$ edition Lippincott-Raven Publishers, Philadelphia. 1997: 219-222.

10. Ihekwaba AE. The Clinical outcome of acute bacterial meningitis at the University of Port Harcourt Teaching Hospital. Nig. Med. Pract. 1990; 20(3): 63-65 